\title{
Influence of Climate Change on the Flood Disasters in Bursa, Turkey
}

\author{
Mustafa Nuri Balov*t \\ *Department of Civil Engineering, Istanbul Gelisim University. Istanbul, Turkey \\ (mustafanuribalov@gmail.com) \\ + Corresponding Author; Istanbul Gelisim University. Istanbul, Turkey \\ Tel: +90 2124227000 / 206, mustafanuribalov@gmail.com
}

Received: 13.10.2020 Accepted: 06.11.2020

\begin{abstract}
The recent increase in the frequency and intensity of the floods resulted from huge precipitation events in Bursa Province, Turkey, is the main motivation of this study. For this purpose, the daily precipitation values from the historical data recorded between 1971 and 2000 together with the projected data of the NorESM1-M general circulation model under RCP4.5 and RCP8.5 scenarios between 2031 and 2100 were used to calculate eight extreme precipitation events. The Spearman's rho and the Mann-Kendall trend tests were used to detect the trend in the indices. The results of the trend tests showed that any change is not expected in the total amount of the yearly precipitation amount, whereas the occurrence of the intense and short duration precipitation events is expected to be more probable by the end of the current century, compared to the last 30 years of the previous century. The positive significant trends were detected in some indices. However, the magnitude of the change in the climatic parameters and the increase in the number of extreme precipitation events cannot solely explain the increase in the number of destroying flood events in the province. Other parameters such as the dramatic increase in urbanization as a result of rapid population growth during the past years (since 1960) may have a more prominent effect on the increase of the flood risk in the province which is in need of comprehensive modeling and investigation.
\end{abstract}

Keywords: Climate change, Bursa, Turkey, GCM, Trend analyses, Extreme Precipitation

\section{Introduction}

The extreme climatic events such as heavy precipitation events have been now an important part of human life, due mainly to climate change. Now a day, it is more common to hear some news about floods and their negative effects on human life all around the world. At the time of writing this paper (Summer 2020) some countries including China and Japan, were suffering the flood destructions. To diminish the effects of natural disasters it is important to have scientific and rational knowledge of the climate system to make decisions on the adaptive and mitigative actions. The reliable modeling of the climate system has approved the effects of human activities on the dramatic growth in the occurrence of extreme climatic events during the recent years according to the Intergovernmental Panel on Climate Change [1]. Floods which are a consequence of heavy precipitation events are now more common in many countries than in the last 50 years. In this case, for some regions, although the total annual precipitation amount has remained constant, the frequency and intensity of the rainfall events have increased which indicates a significant change in the precipitation pattern in those regions [2]. For Turkey, for instance, the projections showed that a decrease is expected in southern parts and a slight increase in the northern parts in the total yearly precipitation amount [3]. On the other hand, as a result of global warming the capacity of the atmosphere to hold water has been increased which lead to an increase in the global precipitation [4-9]. In this context, a common way to have a knowledge of future extreme precipitation events is to investigate the trend in the longduration time series of historical records [10-22]. On the other hand, using the outputs of climate models such as global circulation models (GCMs) can provide a more reliable and more realistic picture of the future. Accordingly, a number of researchers have analyzed the outputs of GCMs under various scenarios in term of extreme precipitation events and the trend detection [23-29].

Various studies have been performed on the trend detection in the climatic parameters in Turkey, based only on the 
historical data [10-12, 18, 22]. In a study [17], three precipitation and three temperature indices were generated based on the long-term records on Euphrates Basin in Turkey. The trend in the indices was examined and the author concluded that the trend in extreme precipitation indices was not significant during the time period of 1970 to 2017 . On the other hand, the number of researches that used the outputs of general circulation models is not a lot [28, 30-31]. In this way, in a study [2] used the outputs of three GCMs under two emission scenarios to generate and trend detection of eight extreme precipitation extreme in the Western Black Sea Basin, Turkey. The results of the study showed that the number of dry and wet days will increase over the basin in spite of the unchanged total precipitation amount.

In this paper, the long-term trend detection of extreme precipitation indices was performed by using the outputs of the NorESM1-M model under RCP4.5 and RCP8.5 scenarios [32] at Osmangazi Station located at Bursa Province, Turkey. Unfortunately, Bursa experienced a huge precipitation event in the middle of June 2020 which results in loss of life and property. Change in the climatic variables will have a direct effect on the frequency and intensity of this type of extreme climatic event. In this study, the effects of the climate change on the extreme precipitation events were analyzed based on the daily measured and projected precipitation values which were used to generate eight extreme precipitation indices, and the trend in that indices was investigated based on the Spearman's rho and the Mann-Kendall trend tests.

\section{Study Area and Data}

The extreme precipitation indices generated by using the historical and projected precipitation values of Osmangazi Station (Figure 1) located in Bursa Province, Turkey. Bursa province has been experienced a dramatic change in terms of land use parallel to industrial development and population growth as a result of migration.

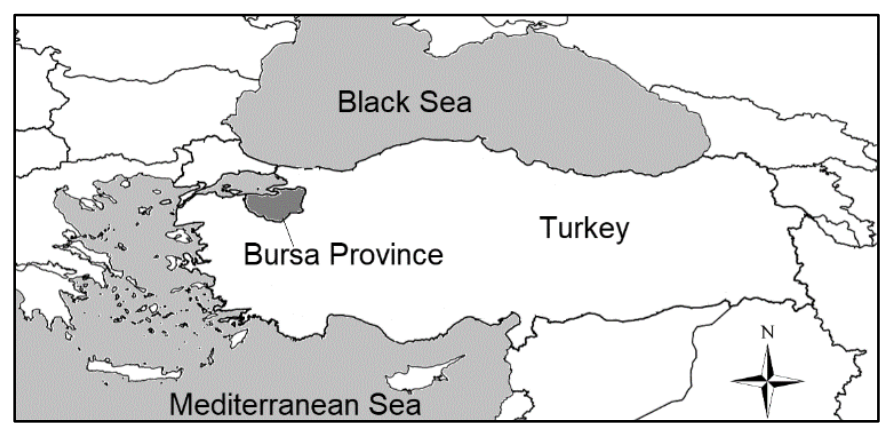

Fig. 1: The study area

The total area of the province is $10882 \mathrm{~km}^{2}$ which 45 percent of it is covered by forests. However, the change in the land cover and the terrestrial feature of the region (Figure 2) increases the vulnerability of the city to flood. On the other hand, the changing climate can make huge precipitation events more frequent and destructive. In this way, the investigation of trends in historical and projected data is important. For the historical data, in this study, the daily precipitation records between 1971 and 2000 belong to the Osmangazi station was obtained. The location is located at $40.2308^{\circ} \mathrm{N}$ and $29.0133^{\circ} \mathrm{E}$ coordinates and the elevation of the station from the sea surface is $100 \mathrm{~m}$. The mean yearly precipitation amount is $721 \mathrm{~mm}$ at that station. On the other hand, the daily projected outputs of NorESM1-M general circulation model (The Norwegian Earth System Model, more information about the model can be found in Bentsen et al. 2013) as a part of Coupled Model Intercomparison Project Phase 5 (CMIP5) under RCP4.5 and RCP8.5 scenarios was downloaded [51]. Unfortunately, the daily time scale of precipitation data made it impossible to use the outputs of various GCMs rather than only one. Nevertheless, the outputs of the selected GCM still can be useful to provide a scientific point of view about the future climate of the region and the extreme precipitation events. The projected data were analyzed in three 30-year time periods: 1971-2000 as the reference period, 2041-2070 as the mid-time future, and 20712100 as the late future.

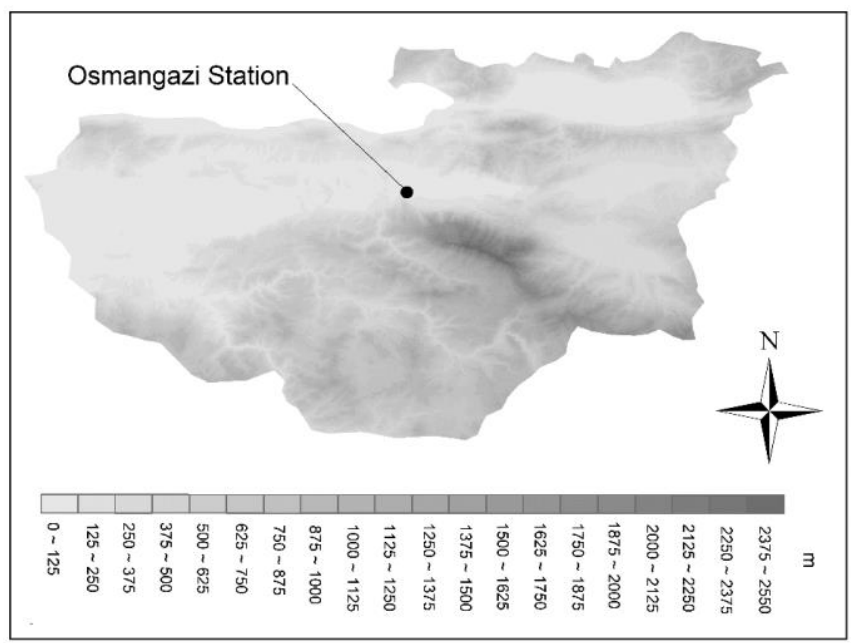

Fig. 2: The topographic map of Bursa Province

\section{Study Approach}

Working with the outputs of GCMs is in need of consideration of uncertainties due mainly to the structure of the model, i.e. the systematic errors [34]. The uncertainty may have rooted in the nature of the climate system also, however, it is not possible to deal with those types of uncertainties in climate change impact studies. In this way, the biases between observed and projected data during the reference period should be corrected by using some methods that are called bias correction methods. Studies show that using an appropriate bias correction method can enhance the outputs of the GCMs [35-41] and as a result, a better understanding of the future climate condition. In this research, the linear scaling bias correction method was adopted to the daily projected precipitation values (the detailed information about the method can be found in [42]). This method is a staticallybased method. The method has successfully applied in climate change impact studies especially when the mean value is the main interest of the correction [43]. 


\subsection{Extreme Precipitation Indices}

The most common way to study the extreme precipitation events is to apply non-parametric extreme precipitation indices recommended by ETCCDI [44]. The eight extreme precipitation indices used in this study are presented in Table 1. The indices were generated by using the daily observed and projected precipitation data.

\subsection{Trend Tests}

In this study two commonly used trend tests in hydrological studies were applied to detect the trend in the extreme precipitation indices generated by using the daily precipitation values from observed and projected values for the reference period (1971-2000) and projected values for the future period (2031-2100). These tests are the Mann-Kendall [45-46], and the Spearman's rho (SR). More detailed information about the test can be found in [3] and [47].

\section{Results and Discussion}

To evaluate the trend in time series, firstly, the criterion of the assessment should be defined. In this way, the positivity and negativity of the value of the trend test show how the trend is increasing or decreasing respectively. On the other hand, the significance of the trend can be determined by choosing an appropriate level of significance and corresponding critical value. Accordingly, the critical values for the Mann-Kendall and Spearman's rho test based on the number of the samples which are 30 for the reference period and 70 for the future period are presented in Table 2.

Table 1: The extreme precipitation indices. significant based on the level of significance of 0.1. In the table, the strength of the trend for PRCPTOT (the total precipitation) was found to be non-significant during the reference period based on the observed and projected data. However, a decreasing trend was detected for the future period which is in accord with the difference in the mean value of PRCPTOT in the last 30 years of the previous and current century, as can be seen in Table 4. The value of PRCPTOT was found to be 694.83 $\mathrm{mm}$ which is projected to decrease to $683.61 \mathrm{~mm}$ and 659.59 $\mathrm{mm}$ based on the outputs of GCM under RCP4.5 and RCP8.5 respectively by the end of the century. However, considering the uncertainties in the climate models it can be said that the total amount of precipitation is projected as unchanged during the current century compare to the previous years. On the other hand, an increasing trend was detected in the value of RX1day and RX2day. This condition can be explained by the change in the precipitation pattern rather than the total precipitation amount. The difference between the 30-year mean value of those two indices (also other indices but PRCPTOT and CDD) calculated by using the observed and projected value for the reference period (1971-2000) indicates the high level of uncertainty in the outputs of the GCM which has not waned after bias correction. As indicated before, the linear scaling method of bias correction leads to more reliable results in terms of mean values not all statistical properties or distribution of the daily precipitation values, which resulted in the different value of extreme precipitation indices concerning the observation values. Nevertheless, the results can picture the future condition of the climatic parameter under consideration of the level of uncertainty. In this way, the comparison can be established on the values of GCM for the reference and future periods, where an approximately $25 \%$ increase in the values of RX1day and RX2day was projected according to the values of Table 4. Accordingly, rainfall events with high intensity and short duration will be the main properties of the precipitation pattern in the region.

\begin{tabular}{|l|l|}
\hline Index & Interpretation \\
\hline PRCPTOT & Total precipitation in wet days $(>1 \mathrm{~mm})$ \\
\hline SDII & simple daily intensity index: Mean precipitation amount on a wet day \\
\hline RX1day & maximum one-day precipitation: Highest precipitation amount in one-day period \\
\hline RX5day & maximum five-day precipitation: Highest precipitation amount in five-day period \\
\hline CDD & consecutive dry days: Maximum length of dry spell (RR $<1 \mathrm{~mm})$ \\
\hline CWD & consecutive wet days: Maximum length of wet spell (RR $\geq 1 \mathrm{~mm})$ \\
\hline R10mm & heavy precipitation days: Count of days where RR (daily precipitation amount) $\geq 10 \mathrm{~mm}$ \\
\hline R20mm & very heavy precipitation days: Count of days where RR $\geq 20 \mathrm{~mm}$ \\
\hline
\end{tabular}

Table 2: The critical value for the level of significance

\begin{tabular}{|c|c|c|c|}
\hline \multirow{2}{*}{$\begin{array}{l}\text { Level of } \\
\text { significance }\end{array}$} & $\begin{array}{l}\text { Number of } \\
\text { samples }\end{array}$ & \multicolumn{2}{|c|}{ The critical value } \\
\cline { 2 - 4 } & 30 & MK & spr \\
\hline \multirow{2}{*}{0.01} & 70 & 2.576 & 2.457 \\
\hline \multirow{2}{*}{0.05} & 30 & 1.96 & 2.374 \\
\cline { 2 - 4 } & 70 & 1.96 & 1.697 \\
\hline \multirow{2}{*}{0.1} & 30 & 1.645 & 1.31 \\
\cline { 2 - 4 } & 70 & 1.645 & 1.292 \\
\hline
\end{tabular}

The results of the trend test for various indices and datasets are presented in Table 3 . The bolded values were found to be
This condition can be also interpreted from the results of the trend test for the SDII index. This index is defined as the average precipitation amount on a wet day. An increasing trend was detected for the values of this index which can be considered as a strong positive trend based on the outputs of the GCM under the RCP8.5 scenario.

The increase in the 30-year mean value of the SDII calculated from the observed and projected value can be seen in Table 4, concerning the relatively high level of uncertainty in the projected values. When the values of SDII calculated from the outputs of the GCM for the reference (1971-2000) and the late future (2071-2100) periods were compared, one can estimate the change by the end of the century considering the 
difference between observed $(6.97 \mathrm{~mm})$ and modeled $(4.13$ $\mathrm{mm}$ ) values for the reference period.

$\mathrm{R} 10 \mathrm{~mm}$ and $\mathrm{R} 20 \mathrm{~mm}$ indices also are two beneficial tools for the estimation of magnitude of the extreme precipitation events. The results of the trend test for these two indices showed a different manner, where the trend in R10mm was found to be not significant while an increasingly strong trend was detected for R20mm based on both the observed and the modeled values. The number of days with heavy precipitation events has been increased and it is expected to continue to increase based on the outputs of the GCM under RCP4.5 and RCP8.5 scenarios. On the other hand, the number of consecutive dry and wet days is expected to remain unchanged during the coming years.

Figure 3 presents the graphical illustration of the projected indices for the time period between 2031 and 2100, based on the outputs of the GCM under RCP4.5 and RCP8.5 scenarios.

Table 3: The results of trend test for the Osmangazi station extreme precipitation indices vary from index to index. However, concerning the level of uncertainty in the outputs of the GCM and lack of the large number of GCMs because of high temporal resolution which is needed in the study of the extreme precipitation events, one can interpret that by the end of the current century the huge precipitation events will be more probable, while the total amount of the precipitation will approximately remain unchanged.

On the other hand, the growth in the frequency and magnitude of floods in Bursa is in direct relation with some other factors such as the runoff coefficient which is a function of land cover, rather than the effects of climate change only. According to a study [49], the percentage of urbanization of the Bursa Province has increased from up to 40 in 1960 to up to 80 in 2000. Additionally, the population of the province has increased from approximately 2 million in 2000 to more than 3 million in 2019 based on the population values released by the Turkish Statistics Institute [51]. Therefore, it seems that the dramatic increase in the population and urbanization may has more impact on the increase of flood risk and flood destruction together with climate change.

\begin{tabular}{|l|c|c|c|c|c|c|c|c|c|c|}
\hline \multirow{2}{*}{ Dataset } & \multirow{2}{*}{ period } & \multirow{2}{*}{ test } & \multicolumn{9}{|c|}{ Index } \\
\cline { 3 - 11 } & & PRCPTOT & SDII & RX1day & RX5day & CDD & CWD & R10mm & R20mm \\
\hline \multirow{2}{*}{ Observation } & \multirow{2}{*}{$1971-2000$} & $\mathrm{MK}$ & 0 & 0.571 & 0 & -1.07 & 1.07 & -0.071 & 0.036 & 0.714 \\
\cline { 3 - 11 } & & $\mathrm{spr}$ & -0.025 & 0.651 & 0.126 & -1.045 & $\mathbf{1 . 3 7 3}$ & 0.663 & 0.381 & $\mathbf{1 . 3 3 2}$ \\
\hline \multirow{2}{*}{ GCM_Ref } & \multirow{2}{*}{$1971-2000$} & $\mathrm{MK}$ & 0.393 & 1.07 & -0.321 & 0.393 & -1.088 & 0.071 & 1.053 & 0.071 \\
\cline { 3 - 11 } & & $\mathrm{spr}$ & 0.367 & 1.07 & -0.374 & 0.41 & -0.943 & 0.472 & $\mathbf{1 . 8 0 8}$ & $\mathbf{2 . 4 1 3}$ \\
\hline \multirow{2}{*}{ GCM_RCP4.5 } & \multirow{2}{*}{$2031-2100$} & $\mathrm{MK}$ & -0.193 & 0.426 & 1.632 & 1.572 & 0.512 & -0.183 & 0.223 & 1.085 \\
\cline { 3 - 11 } & $\mathrm{spr}$ & -0.286 & 0.388 & $\mathbf{1 . 3 8 5}$ & $\mathbf{1 . 3 7 6}$ & 0.793 & 0.268 & 0.911 & $\mathbf{3 . 2 4 2}$ \\
\hline \multirow{2}{*}{ GCM_RCP8.5 } & \multirow{2}{*}{$2031-2100$} & $\mathrm{MK}$ & -1.207 & 1.338 & 0.943 & 0.071 & 0.38 & -0.041 & -0.406 & $\mathbf{1 . 6 7 8}$ \\
\cline { 3 - 11 } & & $\mathrm{spr}$ & -1.203 & $\mathbf{1 . 3 8 2}$ & 1.074 & 0.203 & 0.419 & 0.519 & 0.227 & $\mathbf{4 . 6 4 4}$ \\
\hline
\end{tabular}

Table 4: The 30-years average values of the indices

\begin{tabular}{|l|c|c|c|c|c|c|c|c|c|}
\hline \multirow{2}{*}{ Dataset } & \multirow{2}{*}{ period } & \multicolumn{9}{|c|}{ Index } \\
\cline { 3 - 10 } & & PRCPTOT & SDII & RX1day & RX5day & CDD & CWD & R10mm & R20mm \\
\hline Observation & $1971-2000$ & 694.83 & 6.97 & 42.15 & 79.39 & 33.3 & 7.77 & 22.57 & 5.13 \\
\hline GCM_Ref & $1971-2000$ & 671.04 & 4.13 & 20.67 & 51.82 & 31.17 & 14.5 & 11.27 & 0.77 \\
\hline GCM_RCP4.5 & $2071-2100$ & 683.61 & 4.39 & 24.75 & 57.53 & 40.53 & 15.3 & 12.27 & 1.33 \\
\hline GCM_RCP8.5 & $2071-2100$ & 659.59 & 4.47 & 25.27 & 58.98 & 37.93 & 13.67 & 12.2 & 1.57 \\
\hline
\end{tabular}

The results are in accord with the values of the trend tests in Table 3. The slope of the trend lines shown on the graphs represent the significance of the trend in the time series of the indices. The results of trend test in the extreme precipitation events which generated based on the outputs of GCMs for other parts of the country were found to be in accord with the results of this study [3, 30, 31]. For instance, in a study [31] the authors detected a strong increasing trend in majority of extreme indices in a meteorological station (Olimpiyat) in Istanbul, Turkey.

In general, the strength and manner of the trend in the
In this way, it can be useful to have a comprehensive developing plan considering all parameters such as climate change, population, urbanization, infrastructure system, and economic aspects.

\section{Summary and Conclusion}

In this study, the impacts of climate change on the extreme precipitation events were investigated by detection of the trend in eight extreme precipitation indices. The indices were generated by using observed and projected data of a general circulation model under RCP4.5 and RCP8.5 scenarios. The daily precipitation outputs of the NorESM1-M model for the 
period of 2030 to 2100 were used for the generation of the indices. The trend tests were performed by using the MannKendall and Spearman's rho trend tests. The results showed that the change in the total precipitation amount will be nonsignificant, where the pattern of the precipitation is expected to change so that the number of intense and short-duration precipitation events will increase. However, based on the results of the study, it can be indicated that, although increasing trends were detected in the future extreme
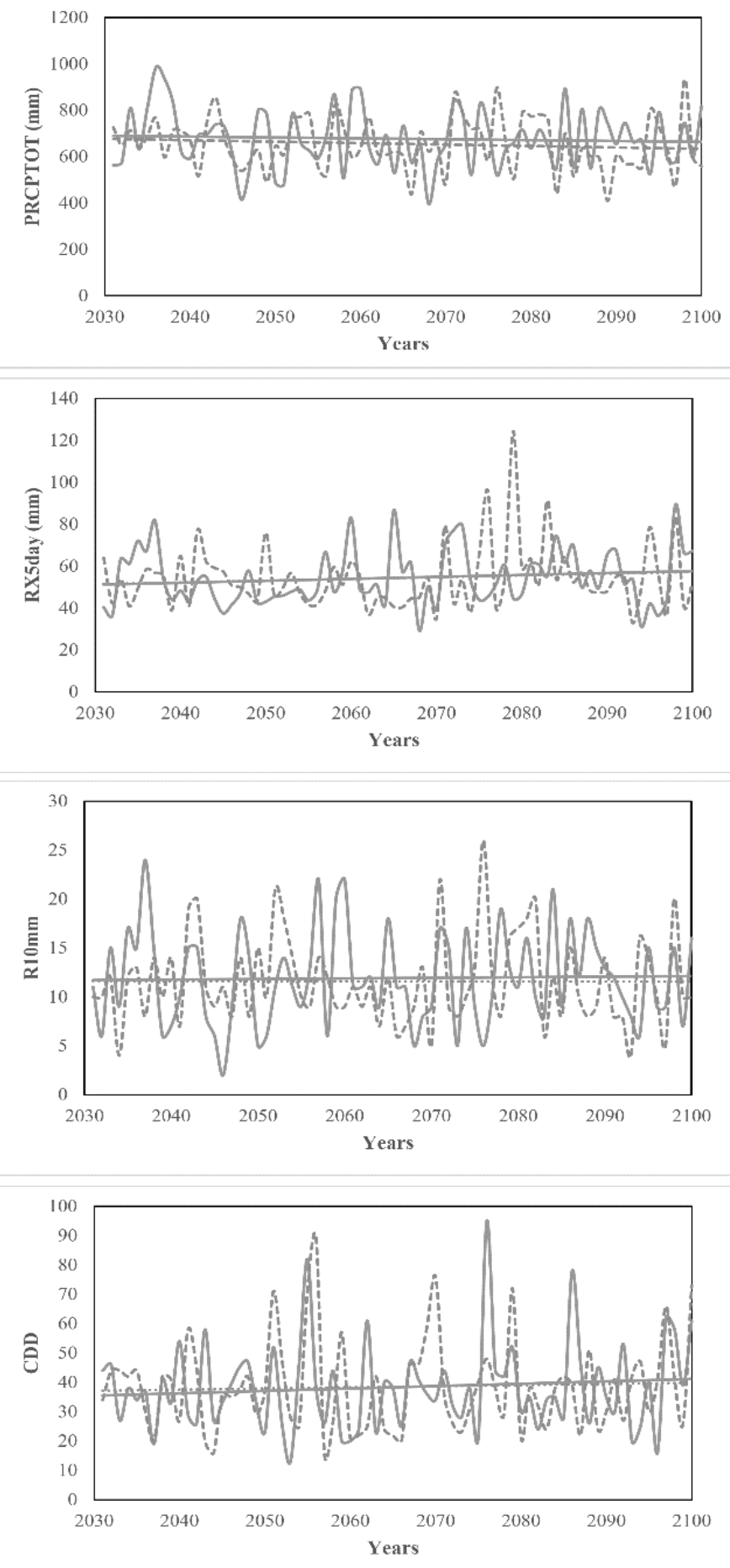

precipitation indices, the effects of urbanization and population growth should be taken into the account for better understanding of the flood risk in the province.
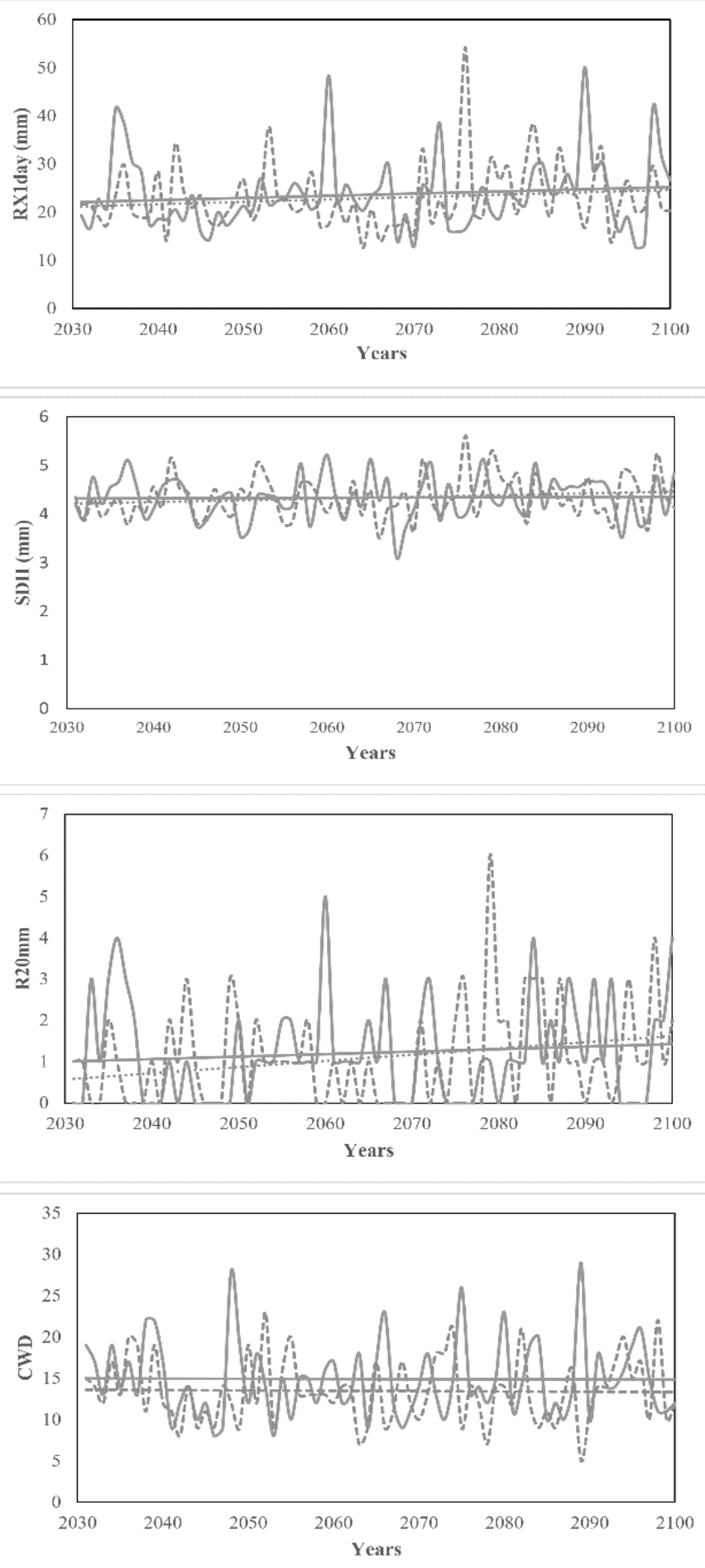

RCP4.5 - - - RCP8.5

Fig. 3: The graphical illustration of projected extreme precipitation indices. 


\section{References}

[1] IPCC, Climate Change 2013: The Physical Sciences Basis. Cambridge University Press, 2013.

[2] M. Nuri Balov and A. Altunkaynak, "Trend Analyses on extreme precipitation indices based on downscaled outputs of global circulation models in Western Black Sea Basin, Turkey," Iran. J. Sci. Technol. Trans. Civ. Eng., 2019.

[3] Ö. L. Şen, A holistic view of climate change and its impacts in Turkey. ISTANBUL POLICY CENTER, 2013.

[4] I. M. Held and B. J. Soden, "Robust responses of the hydrologic cycle to global warming," J. Clim., vol. 19, pp. 5686-5699, 2006, doi: 10.1175/JCLI3990.1.

[5] F. J. Wentz, L. Ricciardulli, K. Hilburn, and C. Mears, "How Much More Rain Will Global Warming Bring? \n10.1126/science.1140746," Science (80-. )., vol. 317, no. 5835, pp. 233-235, 2007, doi: 10.1126/science. 1140746.

[6] F. Lambert, A. Stine, N. Krakauer, and J. Chiang, "How Much Will Precipitation Increase With Global Warming ?," EOS, Trans. Am. Geophys. UNION, vol. 89, no. May 2008, pp. 193-200, 2008, doi: 10.1029/2008EO210001.

[7] K. E. Trenberth, "Changes in precipitation with climate change," Clim. Res., vol. 47, no. 1-2, pp. 123138, 2011, doi: 10.3354/cr00953.

[8] S. Siswanto, G. J. van Oldenborgh, G. van der Schrier, R. Jilderda, and B. van den Hurk, "Temperature, extreme precipitation, and diurnal rainfall changes in the urbanized Jakarta city during the past 130 years," Int. J. Climatol., vol. 36, no. 9, pp. 3207-3225, 2016, doi: $10.1002 /$ joc. 4548 .

[9] M. Nuri Balov and A. Altunkaynak, "Frequency analyses of extreme precipitation events in Western Black Sea Basin (Turkey) based on climate change projections," Meteorol. Appl., vol. 26, no. 3, 2019, doi: 10.1002/met.1776.

[10] B. Oktay Akkoyunlu, H. Baltaci, and M. Tayanc, "Atmospheric conditions of extreme precipitation events in western Turkey for the period 2006-2015," Nat. Hazards Earth Syst. Sci., vol. 19, no. 1, pp. 107 119, 2019, doi: 10.5194/nhess-19-107-2019.

[11] E. E. Arslantaş and E. Yeşilırmak, "Changes in the climatic growing season in western Anatolia, Turkey," Meteorol. Appl., vol. 27, no. 2, pp. 1-16, 2020, doi: 10.1002/met.1897.

[12] H. Baltaci, H. Arslan, B. O. Akkoyunlu, and H. B. Gomes, "Long-term variability and trends of extended winter snowfall in Turkey and the role of teleconnection patterns," Meteorol. Appl., vol. 27, no. 2, pp. 1-14, 2020, doi: 10.1002/met.1891.

[13] E. Guo, Y. Wang, B. Jirigala, and E. Jin, "Spatiotemporal variations of precipitation concentration and their potential links to drought in mainland China," J. Clean. Prod., vol. 267, p. 122004, 2020, doi: 10.1016/j.jclepro.2020.122004.

[14] G. Venkata Rao, K. Venkata Reddy, R. Srinivasan, V. Sridhar, N. V. Umamahesh, and D. Pratap, "Spatio- temporal analysis of rainfall extremes in the floodprone Nagavali and Vamsadhara Basins in eastern India," Weather Clim. Extrem., vol. 29, no. May, p. 100265, 2020, doi: 10.1016/j.wace.2020.100265.

[15] S. I. Hurtado, P. G. Zaninelli, and E. A. Agosta, "A multi-breakpoint methodology to detect changes in climatic time series. An application to wet season precipitation in subtropical Argentina," Atmos. Res., vol. 241, no. November 2019, p. 104955, 2020, doi: 10.1016/j.atmosres.2020.104955.

[16] M. Abbasnia and H. Toros, "Trend analysis of weather extremes across the coastal and non-coastal areas (case study: Turkey)," J. Earth Syst. Sci., vol. 129, no. 1, 2020, doi: 10.1007/s12040-020-1359-3.

[17] P. Bostan, "Assessing variations in climate extremes over Euphrates Basin, Turkey," Theor. Appl. Climatol., pp. 1461-1473, 2020, doi: 10.1007/s00704-020-032389.

[18] A. Y. Sönmez and S. Kale, "Climate change effects on annual streamflow of filyos river (Turkey)," J. Water Clim. Chang., vol. 11, no. 2, pp. 420-433, 2020, doi: 10.2166/wcc.2018.060.

[19] S. Shree, M. Kumar, and A. Singh, "Exploring spatial and temporal trends of diurnal temperature range in the region of the Subarnarekha river basin India," Spat. Inf. Res., 2020, doi: 10.1007/s41324-020-00341-x.

[20] S. Ahmad et al., "Spatio-temporal trends in snow extent and their linkage to hydro-climatological and topographical factors in the Chitral River Basin (Hindukush, Pakistan)," Geocarto Int., vol. 35, no. 7, pp. 711-734, 2020, doi: 10.1080/10106049.2018. 1524517.

[21] A. R. M. Towfiqul Islam, M. S. Rahman, R. Khatun, and $\mathrm{Z}$. Hu, "Spatiotemporal trends in the frequency of daily rainfall in Bangladesh during 1975-2017," Theor. Appl. Climatol., vol. 141, no. 3-4, pp. 869-887, 2020, doi: 10.1007/s00704-020-03244-x.

[22] O. Yagbasan, V. Demir, and H. Yazicigil, "Trend analyses of meteorological variables and lake levels for two shallow lakes in central Turkey," Water (Switzerland), vol. 12, no. 2, pp. 1-16, 2020, doi: 10.3390/w12020414.

[23] S. Chattopadhyay, D. R. Edwards, and Y. Yu, "Contemporary and future characteristics of precipitation indices in the Kentucky River basin," Water (Switzerland), vol. 9, no. 2, pp. 1-20, 2017, doi: 10.3390/w9020109.

[24] S. Peng, Y. Ding, Z. Wen, Y. Chen, Y. Cao, and J. Ren, "Spatiotemporal change and trend analysis of potential evapotranspiration over the Loess Plateau of China during 2011-2100," Agric. For. Meteorol., vol. 233, pp. 183-194, 2017, doi: 10.1016/j.agrformet.2016.11.129.

[25] T. S. Mohan and M. Rajeevan, "Past and future trends of hydroclimatic intensity over the Indian monsoon region," J. Geophys. Res. Atmos., vol. 122, no. 2, pp. 896-909, 2017, doi: 10.1002/2016JD025301.

[26] G. Shivam, M. K. Goyal, and A. K. Sarma, "Indexbased study of future precipitation changes over subansiri river catchment under changing climate," $J$. Environ. Informatics, vol. 34, no. 1, pp. 1-14, 2019, 
doi: 10.3808/jei.201700376.

[27] V. Singh, A. Sharma, and M. K. Goyal, "Projection of hydro-climatological changes over eastern Himalayan catchment by the evaluation of RegCM4 RCM and CMIP5 GCM models," Hydrol. Res., vol. 50, no. 1, pp. 117-137, 2019, doi: 10.2166/nh.2017.193.

[28] M. Nuri Balov and A. Altunkaynak, "Trend Analyses of Extreme Precipitation Indices Based on Downscaled Outputs of Global Circulation Models in Western Black Sea Basin, Turkey," Iran. J. Sci. Technol. - Trans. Civ. Eng., vol. 43, no. 4, 2019, doi: 10.1007/s40996-019-00237-3.

[29] M. L. Wrzesien and T. M. Pavelsky, "Projected Changes to Extreme Runoff and Precipitation Events From a Downscaled Simulation Over the Western United States," Front. Earth Sci., vol. 7, no. January, pp. 1-17, 2020, doi: 10.3389/feart.2019.00355.

[30] A. G. Yilmaz, "The effects of climate change on historical and future extreme rainfall in Antalya, Turkey," Hydrol. Sci. J., vol. 60, no. 12, pp. 2148 2162, 2015, doi: 10.1080/02626667.2014.945455.

[31] T. A. Nigussie and A. Altunkaynak, "Impacts of climate change on the trends of extreme rainfall indices and values of maximum precipitation at Olimpiyat Station, Istanbul, Turkey," Theor. Appl. Climatol., pp. 1-15, 2018, doi: 10.1007/s00704-0182449-x.

[32] R. K. Chaturvedi, J. Joshi, M. Jayaraman, G. Bala, and N. H. Ravindranath, "Multi-model climate change projections for India under representative concentration pathways," Curr. Sci., vol. 103, no. 7, pp. 791-802, 2012, doi: 10.2307/24088836.

[33] M. Bentsen et al., "The Norwegian Earth System Model, NorESM1-M - Part 1: Description and basic evaluation of the physical climate," Geosci. Model Dev., vol. 6, no. 3, pp. 687-720, 2013, doi: 10.5194/gmd-6-687-2013.

[34] N. N. Ishizaki, M. Nishimori, T. Iizumi, H. Shiogama, N. Hanasaki, and K. Takahashi, "Evaluation of two bias-correction methods for gridded climate scenarios over Japan," Sci. Online Lett. Atmos., vol. 16, pp. 80 85, 2020, doi: 10.2151/SOLA.2020-014.

[35] C. M. Lim, Y. Bin Yhang, and S. Ham, "Application of GCM bias correction to RCM simulations of East Asian winter climate," Atmosphere (Basel)., vol. 10, no. 7, 2019, doi: 10.3390/atmos10070382.

[36] A. Casanueva, S. Kotlarski, S. Herrera, A. M. Fischer, T. Kjellstrom, and C. Schwierz, "Climate projections of a multi-variate heat stress index: the role of downscaling and bias correction," Geosci. Model Dev. Discuss., pp. 1-33, 2019, doi: 10.5194/gmd-2018-294.

[37] S. Mohan and P. K. Bhaskaran, "Evaluation and bias correction of global climate models in the CMIP5 over the Indian Ocean region," Environ. Monit. Assess., vol. 191, 2019, doi: 10.1007/s10661-019-7700-0.

[38] J. Das, V. Poonia, S. Jha, and M. K. Goyal, "Understanding the climate change impact on crop yield over Eastern Himalayan Region: ascertaining GCM and scenario uncertainty," Theor. Appl. Climatol., no. 2011, 2020, doi: 10.1007/s00704-020- 03332-y.

[39] A. Goly and R. S. V. Teegavarapu, "Optimization and Variants of Quantile-Based Methods for Bias Corrections of Statistically Downscaled Precipitation Data," J. Hydrol. Eng., vol. 25, no. 7, pp. 1-15, 2020, doi: 10.1061/(ASCE)HE.1943-5584.0001926.

[40] E. Rocheta, J. P. Evans, and A. Sharma, "Correcting lateral boundary biases in regional climate modelling: the effect of the relaxation zone," Clim. Dyn., no. 2017, 2020, doi: 10.1007/s00382-020-05393-1.

[41] M. Mendez, B. Maathuis, D. Hein-Griggs, and L. F. Alvarado-Gamboa, "Performance evaluation of bias correction methods for climate change monthly precipitation projections over Costa Rica," Water (Switzerland), vol. 12, no. 2, 2020, doi: 10.3390/w12020482.

[42] M. Nuri Balov and A. Altunkaynak, "Spatio-temporal evaluation of various global circulation models in terms of projection of different meteorological drought indices," Environ. Earth Sci., vol. 79, no. 6, pp. 1-13, 2020, doi: 10.1007/s12665-020-8881-0.

[43] R. Das Bhowmik and A. Sankarasubramanian, "Limitations of univariate linear bias correction in yielding cross-correlation between monthly precipitation and temperature," Int. J. Climatol., vol. 39, no. 11, pp. 4479-4496, 2019, doi: 10.1002/joc.6086.

[44] A. A. Akinsanola, G. J. Kooperman, A. G. Pendergrass, W. M. Hannah, and K. A. Reed, "Seasonal representation of extreme precipitation indices over the United States in CMIP6 present-day simulations," Environ. Res. Lett., vol. 15, no. 9, p. 094003, 2020, doi: 10.1088/1748-9326/ab92c1.

[45] H. B. Mann, "Nonparametric Tests Against Trend," Econometrica, vol. 13, no. 3, p. 245, Jul. 1945, doi: 10.2307/1907187.

[46] M. G. Kendall, Rank Correlation Methods. 4th Edition. 1957.

[47] R. Sahu and R. D. Gupta, "Glacier mapping and change analysis in Chandra basin, Western Himalaya, India during 1971-2016," Int. J. Remote Sens., vol. 41, no. 18, pp. 6914-6945, 2020, doi: 10.1080/01431161.2020.1752412.

[48] A. G. Yilmaz, "Climate change effects and extreme rainfall non-stationarity," vol. 170, 2016.

[49] M. M. Yüceşahin, R. Bayar, and E. M. Özgür, “TÜRKIYE'DE ŞEHIRLEŞMENIN MEKANSAL DAĞILIŞI ve DEĞIŞìi Spatial Distribution of Urbanization and Its Change in Turkey," Coğrafi Bilim. Derg., vol. 2, no. June, pp. 23-39, 2004.

https://climate4impact.eu/impactportal/data/esgfsearc h.jsp\#project=CORDEX-Adjustand

http://www.turkstat.gov.tr/Start.do;jsessionid=nm2Cf4 JDhQ3bYDpyd5LTq9f2ZhJKsDyfrDwZPY2Ny0NX KSGymg18!1132332831 